\title{
Depressive symptoms in spouses of older patients with severe sepsis*
}

\author{
Dimitry S. Davydow, MD, MPH; Catherine L. Hough, MD, MSc; Kenneth M. Langa, MD, PhD; \\ Theodore J. Iwashyna, MD, PhD
}

Objective: To examine whether spouses of patients with severe sepsis are at increased risk for depression independent of the spouse's presepsis history, whether this risk differs by sex, and is associated with a sepsis patient's disability after hospitalization.

Design: Prospective longitudinal cohort study.

Setting: Population-based cohort of U.S. adults over 50 yrs old interviewed as part of the Health and Retirement Study (1993-2008).

Patients: Nine hundred twenty-nine patient-spouse dyads comprising 1,212 hospitalizations for severe sepsis.

Measurements and Main Results: Severe sepsis was identified using a validated algorithm in Medicare claims. Depression was assessed with a modified version of the Center for Epidemiologic Studies Depression Scale. All analyses were stratified by gender. The prevalence of substantial depressive symptoms in wives of patients with severe sepsis increased by 14 percentage points at the time of severe sepsis (from $20 \%$ at a median of 1.1 yrs presepsis to $34 \%$ at a median of $1 \mathrm{yr}$ postsepsis) with an odds ratio of 3.74 (95\% confidence interval: $2.20,6.37)$, in multivariable regression.
Husbands had an 8 percentage point increase in the prevalence of substantial depressive symptoms, which was not significant in multivariable regression (odds ratio $1.90,95 \%$ confidence interval $\mathbf{0 . 7 5}, 4.71)$. The increase in depression was not explained by bereavement; women had greater odds of substantial depressive symptoms even when their spouse survived a severe sepsis hospitalization (odds ratio $2.86,95 \%$ confidence interval $1.06,7.73$ ). Wives of sepsis survivors who were disabled were more likely to be depressed (odds ratio $\mathbf{1 . 3 5}$ per activities of daily living limitation of sepsis survivor, 95\% confidence interval 1.12, 1.64); however, controlling for patient disability only slightly attenuated the association between sepsis and wives' depression (odds ratio $2.61,95 \%$ confidence interval $0.93,7.38$ ).

Conclusions: Older women may be at greater risk for depression if their spouse is hospitalized for severe sepsis. Spouses of patients with severe sepsis may benefit from greater support and depression screening, both when their loved one dies and when their loved one survives. (Crit Care Med 2012; 40: 2335-2341)

Key WoRds: caregivers, critical care, depression, outcome assessment (healthcare), sepsis, spouses
$\mathrm{H}$ undreds of thousands of Americans are hospitalized for the treatment of severe sepsis annually, making it the most common noncardiac cause of critical illness (1). Recently, it has been identified that patients who survive severe sepsis have diminished quality of life (2) and are at increased risk

*See also p. 2506.

From the Departments of Psychiatry and Behavioral Sciences (DSD) and Medicine (CLH), University of Washington, Seattle, WA; Department of Internal Medicine (KML,TJI) and the Institute for Social Research (KML,TJI), University of Michigan, Ann Arbor, $\mathrm{Ml}$; and the Ann Arbor Veterans Affairs Center for Clinical Management Research (KML,TJI), Ann Arbor, MI.

The Health and Retirement Study is performed at the Institute for Social Research, University of Michigan.

The authors have not disclosed any potential conflicts of interest.

Supported, in part, by grants KL2 RR025015-05, K08 HL091249, R01 AG030155, and U01 AG09740 from the National Institutes of Health.

For information regarding this article, Email: ddavyd01@u.washington.edu

Copyright (C) 2012 by the Society of Critical Care Medicine and Lippincott Williams \& Wilkins

DOl: 10.1097/CCM.0b013e3182536a81 of new cognitive impairments as well as functional limitations (3). Furthermore, patients who survive severe sepsis have high rates of depression both before and after their sepsis-related hospitalization (4).

Although knowledge is increasing about the emotional well-being of survivors of severe sepsis, relatively little is known about the emotional toll severe sepsis takes on those patients' loved ones. Patients with severe sepsis often require treatment in an intensive care unit (ICU) (1), which can be an extremely stressful experience for their family members (5). Prior studies have identified that some family members of critically ill patients can have high rates of depressive symptoms (5-9). Ascertaining the mental health of loved ones of critically ill patients is of particular importance because depression in family members could affect end-of-life care decisions in the ICU (5), and depression could impact a loved one's ability to care for a critical illness survivor following their hospitalization (10). The latter point is particularly salient among survivors of severe sepsis, many of whom face levels of cognitive impairment and functional limitations that greatly increase the amount of caregiving they require $(3,11)$.

Although family members of severe sepsis patients may be at increased risk of depression, it is unknown to what extent this risk is due to the increased mortality of sepsis patients (1), the ongoing disability that can occur after sepsis (3), or other aspects of the experience of sepsis. Also, it is unknown whether this risk of depression in family members of severe sepsis patients is independent of their own depression history prior to the patient's sepsis hospitalization. Furthermore, although community-dwelling older women have higher rates of depression compared to men (12), it is unclear whether wives of severe sepsis patients are at greater risk of depression than their husbands.

The present study uses an ongoing longitudinal cohort of older Americans to examine whether husbands and wives of patients with severe sepsis are at risk for depression independent of their own prior history, if this risk is affected by whether 
a patient survives severe sepsis, and if this risk is associated with a sepsis patient's disability following a sepsis hospitalization. This approach is novel and offers the distinct advantages of national scope and prospective assessment of depressive symptoms with a consistent instrument, avoiding the challenges of using proxy or retrospective assessment of baseline symptoms (13).

\section{MATERIALS AND METHODS}

Study Population. Our study cohort comes from the Health and Retirement Study (HRS), a nationally representative, longitudinal investigation of community-dwelling U.S. adults > 50 yrs of age. The study began in 1992, and to date over 27,000 individuals have participated. Subjects (and their spouses if married) are reinterviewed every 2 yrs. The follow-up rate for the HRS has exceeded $90 \%$ to $95 \%$, including proxies (14), and 16,772 participants have consented for linkage of their Medicare claims records with study data. The HRS protocol was approved by the University of Michigan Institutional Review Board. Study participants provided informed consent upon enrollment and again for linkage to Medicare claims.

The present study examines patient-spouse dyads with at least one HRS interview from 1993 to 2008 and for whom the patient had Medicare claims-based data for a subsequent hospitalization for severe sepsis from 1993 to 2008. All patients and/or their spouses were followed up through death or the 2008 HRS wave. Data were analyzed for up to three HRS interviews prior to severe sepsis and up to four interviews after severe sepsis.

Demographic and Clinical Characteristics. We obtained data on patient and spouse demographics (i.e., age, self-reported race and ethnicity, sex, education, employment status), alcohol use, and smoking from the HRS interviews.

Baseline chronic medical conditions in spouses (Elixhauser comorbidity measures) (15), as well as clinical characteristics of the severe sepsis hospitalization, including an organ dysfunction score (the sum of the number of organ failures of cardiovascular, neurologic, hematologic, hepatic, renal, or respiratory origin) $(1,16)$ and length of stay for the severe sepsis hospitalization, were abstracted from the Medicare claims.

Definition of Severe Sepsis. We used a clinically validated and widely used claims-based definition of severe sepsis $(1,17-20)$. The definition requires evidence of a concomitant infection and new-onset organ dysfunction during a single hospitalization, consistent with the international consensus conference definitions of severe sepsis (18). We focus on severe sepsis as a single syndrome, rather than the underlying infectious processes, in line with current thought that emphasizes the importance of the common host response in the pathogenesis, treatment, and outcome of severe sepsis (21-24). For patients who had more than one distinct hospitalization for sepsis, each hospitalization was included, with appropriate adjustment of the standard errors as described below.

Depressive Symptoms. The HRS assessed depressive symptoms at each wave with an eight-item version of the Center for Epidemiologic Studies Depression Scale (25). Prior studies have reported that this modified version loses little of the structure and precision of the original scale $(26,27)$. Using a cutoff of $\geq 3$ has been found to have a sensitivity of $71 \%$ and specificity of $79 \%$ for the diagnosis of major depression compared to structured diagnostic interview (28). We used a cutoff score of $\geq 4$ on the eight-item Center for Epidemiologic Studies Depression Scale to define substantial depressive symptoms because this threshold was estimated to be comparable to the cutoff score of $\geq 16$ on the full Center for Epidemiologic Studies Depression Scale by HRS investigators (29) and has been used in several prior studies (30-32).

Disability. To examine disability, respondents (or their proxies) were asked at each interview whether they required assistance with any of six activities of daily living (ADLs): walking, dressing, bathing, eating, getting into or out of bed, and toileting.

Statistical Analysis. Because major depression is more prevalent among older women than men (12), and given an extensive sociological literature on gender differences in caregiving and bereavement (33), we stratified all analyses by gender.

Our unit of analysis for all analyses was the hospitalization. For unadjusted analyses, we grouped spouses of patients with severe sepsis hospitalizations by the number of HRS interviews that they completed after the hospitalization. For example, we compared all spouses at

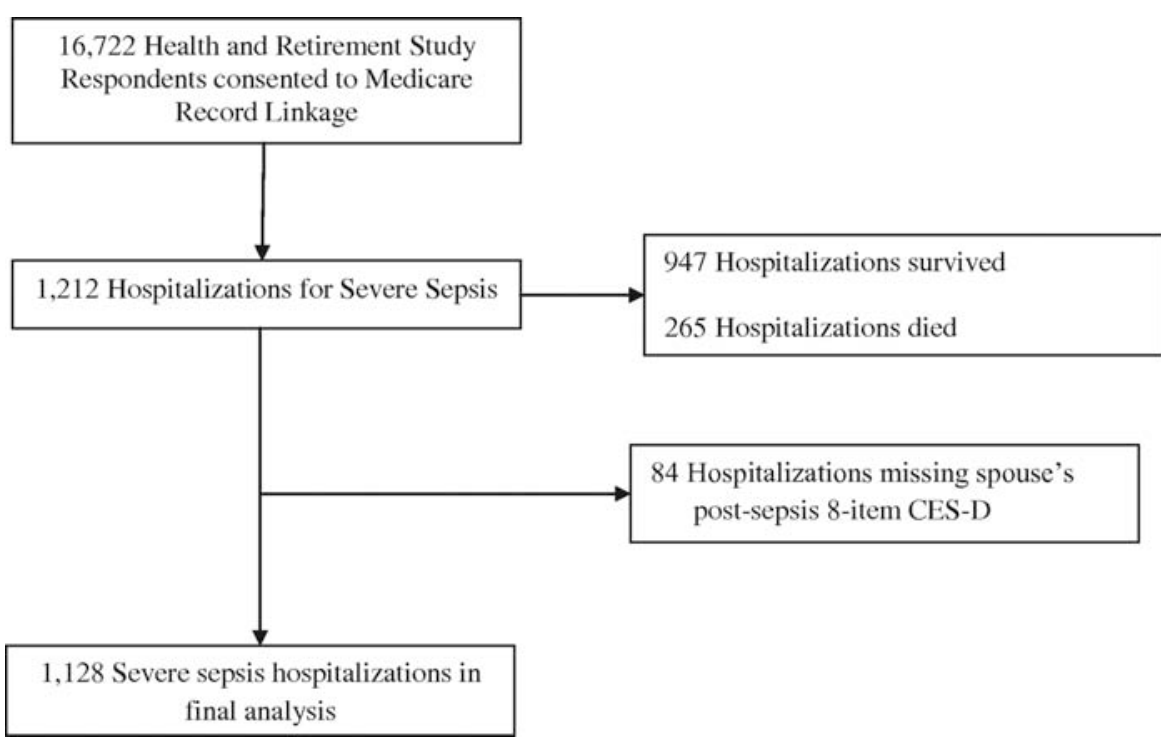

Figure 1. Health and retirement study cohort for analyses of depression in spouses of severe sepsis patients. CES-D, Center for Epidemiologic Studies Depression Scale. the most recent interview before the patient's severe sepsis episode with spouses at their first interview after the patient's hospitalization.

To test the hypothesis that severe sepsis is associated with an increased risk of substantial symptoms of depression among patients' spouses using multivariable models, we used so-called fixed effects logistic regression models that use the longitudinal nature of the data to control for all stable characteristics of the spouses (3). Our data were organized at the interview level, one line per interview per severe sepsis hospitalization. Our independent variable was time from admission date for severe sepsis, measured to the day of each interview, as a continuous variable. We allowed the rate of developing substantial depressive symptoms per unit time to change from before sepsis to afterward by parameterizing time as a linear spline with a knot at the day of admission for the severe sepsis hospitalization. We also included a dichotomous indicator variable that distinguished interviews prior to the severe sepsis hospitalization date from interviews after, grouping spouses by the number of interviews they had completed since the patient's severe sepsis episode. We used a hospitalization-level fixed effect, sometimes called conditional models (34). This definition of "fixed effects" is different from the term "fixed effect" referring to regression seen commonly in the biostatistical literature (35). These results controlled for the spouse's depressive symptom status before the patient's severe sepsis episode. In other words, spouses served as their own controls. Only within-person variation over time was used to estimate the effect of severe sepsis on spouses. No parameters or limitations were set on the hospitalization-specific intercept terms, thus making these models very flexible. This analysis was implemented using clogit in STATA 11 (Stata Corporation, College Station, TX). 
To examine the extent that levels of spousal postsepsis depressive symptoms were affected by patient mortality, we performed an analysis where we stratified by whether or not the patient survived severe sepsis. Finally, to study whether the risk of substantial depressive symptoms in spouses of patients who survived severe sepsis was associated with the degree of patient disability after sepsis, we performed an analysis in which we adjusted for the number of ADL impairments that a severe sepsis survivor had.

We used two-sided significance tests for all analyses with statistical significance set at $p=.05$. Analyses were performed with appropriate components of the IBM SPSS Statistics 18 (SPSS, Chicago, IL) and STATA 11 (Stata Corporation) statistical software programs.

\section{RESULTS}

From 1993 to 2008, 929 HRS respondents had a spouse who was hospitalized for severe sepsis, comprising 1,212 hospitalizations for severe sepsis during that time period (Fig. 1). Slightly more than one fifth of the patients required their spouse to serve as a proxy respondent. Just over one fifth of the severe sepsis hospitalizations ended in patient death (Table 1). Table 1 describes the baseline characteristics of patients and spouses as well as clinical characteristics of the severe sepsis-related hospitalization. Spouses were followed for up to three interviews before severe sepsis (mean of 5.1 yrs) and four interviews after severe sepsis (mean of $7 \mathrm{yrs}$ ). Of the hospitalizations, 865 (93\%) spouses completed at least one follow-up depression assessment.

Pre- and Postsepsis Depressive Symptoms among Spouses. Figure 2 presents the prevalence of substantial depressive symptoms in wives who had a husband hospitalized for severe sepsis before and after sepsis. The prevalence of substantial depressive symptoms among wives increased from $20 \%$ (95\% confidence interval [CI] 17\%, $23 \%$ ) at the most recent interview before sepsis, a median of 1.1 yrs presepsis, to $34 \%$ $(95 \%$ CI $30 \%, 37 \%)$ at the first interview after severe sepsis, a median of 1 yr later (14 percentage point increase, $p<.001$ by chi-square test). Among husbands, the prevalence of substantial depressive symptoms increased from $17 \%$ (95\% CI $13 \%$, $21 \%$ ) at the most recent interview before severe sepsis to $25 \%$ (95\% CI 20\%, 31\%) at the first interview after sepsis (8 percentage point increase, $p<.001$ by chi-square test) (Fig. 3).

Effects of Severe Sepsis on Subsequent Substantial Depressive Symptoms among Spouses. In fixed effects logistic

Table 1. Characteristics of patients and spouse dyads comprising severe sepsis hospitalizations

\begin{tabular}{|c|c|}
\hline Variables & $\mathrm{n}=1212$ \\
\hline \multicolumn{2}{|c|}{ Panel A: Patient characteristics (baseline $e^{a}$ and severe sepsis episode clinical factors) } \\
\hline Age (yrs) & $73.4(8.3)$ \\
\hline Male & $790(65.2 \%)$ \\
\hline \multicolumn{2}{|l|}{ Race } \\
\hline White & $996(82.2 \%)$ \\
\hline Black & $194(16.0 \%)$ \\
\hline Other & $22(1.8 \%)$ \\
\hline \multicolumn{2}{|l|}{ Highest level of education } \\
\hline High school diploma or less & $1050(86.6 \%)$ \\
\hline 2- or 4-yr college degree & $97(8.0 \%)$ \\
\hline Masters or professional degree & $65(5.4 \%)$ \\
\hline Employed & $137(11.3 \%)$ \\
\hline Alcohol use (days/week) & $0.9(2.0)$ \\
\hline \multicolumn{2}{|l|}{ Smoking status } \\
\hline Never smoked & $350(28.9 \%)$ \\
\hline Former smoker & $702(57.9 \%)$ \\
\hline Current smoker & $160(13.2 \%)$ \\
\hline Activities of daily living impairments & $1.6(2.1)$ \\
\hline \multicolumn{2}{|l|}{ Severe sepsis episode clinical factors } \\
\hline Hospital length of stay (days) & $12.1(12.8)$ \\
\hline Organ dysfunction score & $1.3(0.6)$ \\
\hline Cardiovascular dysfunction & $304(25.1 \%)$ \\
\hline Neurologic dysfunction & $104(8.6 \%)$ \\
\hline Hematologic dysfunction & $224(18.5 \%)$ \\
\hline Hepatic dysfunction & $13(1.1 \%)$ \\
\hline Renal dysfunction & $494(40.8 \%)$ \\
\hline Respiratory dysfunction & $370(30.5 \%)$ \\
\hline Died during severe sepsis hospitalization & $265(21.9 \%)$ \\
\hline More than one distinct sepsis hospitalization & $284(23.4 \%)$ \\
\hline \multicolumn{2}{|l|}{ Panel B: Spouse baseline characteristics ${ }^{a}$} \\
\hline Age (yrs) & $71.3(9.5)$ \\
\hline Female & $791(65.3 \%)$ \\
\hline \multicolumn{2}{|l|}{ Race } \\
\hline White & $1000(82.5 \%)$ \\
\hline Black & $189(15.6 \%)$ \\
\hline Other & $23(1.9 \%)$ \\
\hline \multicolumn{2}{|l|}{ Highest level of education } \\
\hline High school diploma or less & $1045(86.2 \%)$ \\
\hline 2 - or 4-yr college degree & $122(10.1 \%)$ \\
\hline Masters or professional degree & $45(3.7 \%)$ \\
\hline Employed & $242(20.0 \%)$ \\
\hline Alcohol use (days/wk) & $0.8(1.8)$ \\
\hline \multicolumn{2}{|l|}{ Smoking Status } \\
\hline Never smoked & $548(45.2 \%)$ \\
\hline Former smoker & $453(37.4 \%)$ \\
\hline Current smoker & $211(17.4 \%)$ \\
\hline \multicolumn{2}{|l|}{ Elixhauser chronic medical conditions } \\
\hline Congestive heart failure & $48(4.0 \%)$ \\
\hline Diabetes mellitus & $84(6.9 \%)$ \\
\hline Chronic pulmonary disease & $81(6.7 \%)$ \\
\hline Peripheral vascular disease & $44(3.6 \%)$ \\
\hline Neurologic disorders & $98(8.1 \%)$ \\
\hline Cancer & $30(2.5 \%)$ \\
\hline Collagen vascular disease & $36(3.0 \%)$ \\
\hline Activities of daily living impairments & $0.6(1.3)$ \\
\hline
\end{tabular}

${ }^{a}$ Patient and spouse baseline characteristics are from the last health and retirement study interview before the severe sepsis hospitalization.

All values are mean \pm SD or $n(\%)$ unless otherwise indicated.

regression, which controls for all spousal characteristics that do not change over time, having a husband hospitalized for severe sepsis was associated with 3.74 times the odds $(95 \%$ CI $2.20,6.37)$ of subsequent substantial depressive symptoms among wives (Table 2). However, having a wife hospitalized for severe sepsis was not significantly associated with subsequent substantial depressive symptoms among husbands, although there is a large CI for the estimate (odds ratio $1.90,95 \%$ CI $0.75,4.71$ ) (Table 3 ). Women continued to have greater odds of substantial depressive symptoms even when their spouse survived a severe sepsis hospitalization (odds ratio 2.86, 95\% CI 1.06, 7.73). 


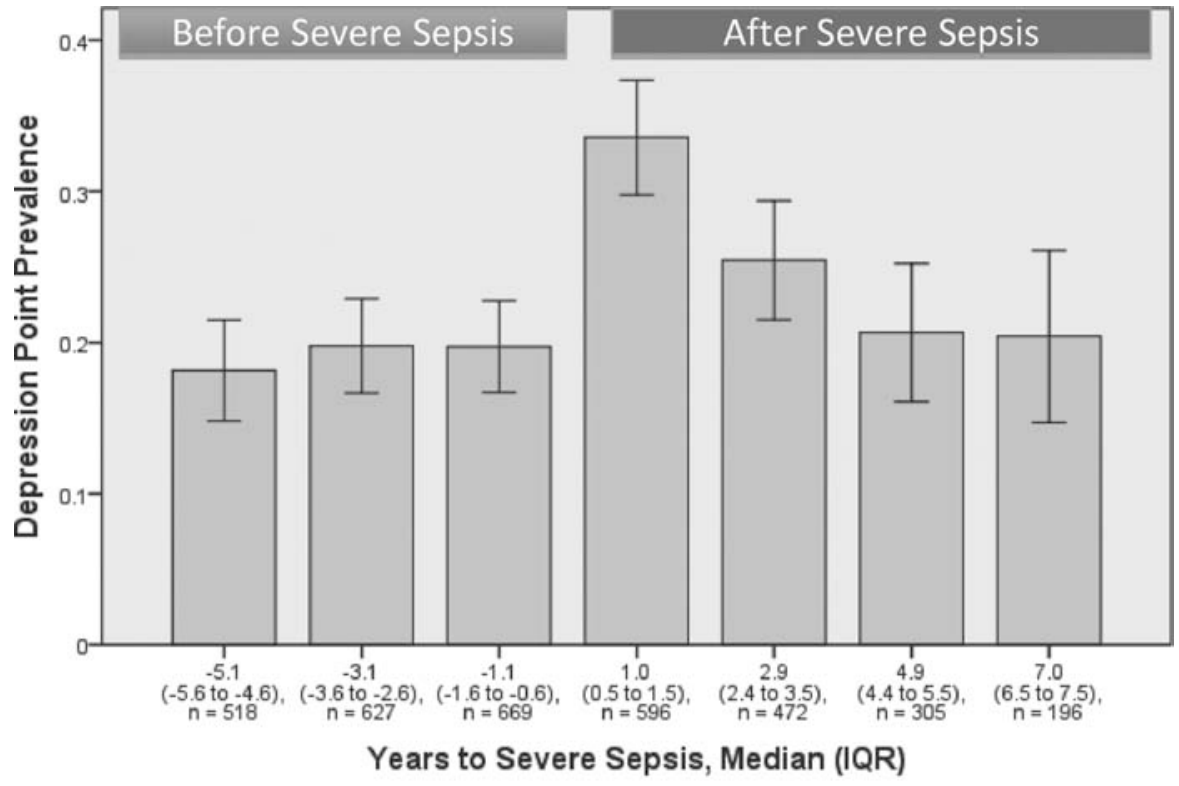

Error bars: $95 \% \mathrm{Cl}$

Figure 2. Prevalence of substantial depressive symptoms among wives of patients with severe sepsis. $I Q R$, interquartile range; $C I$, confidence interval.

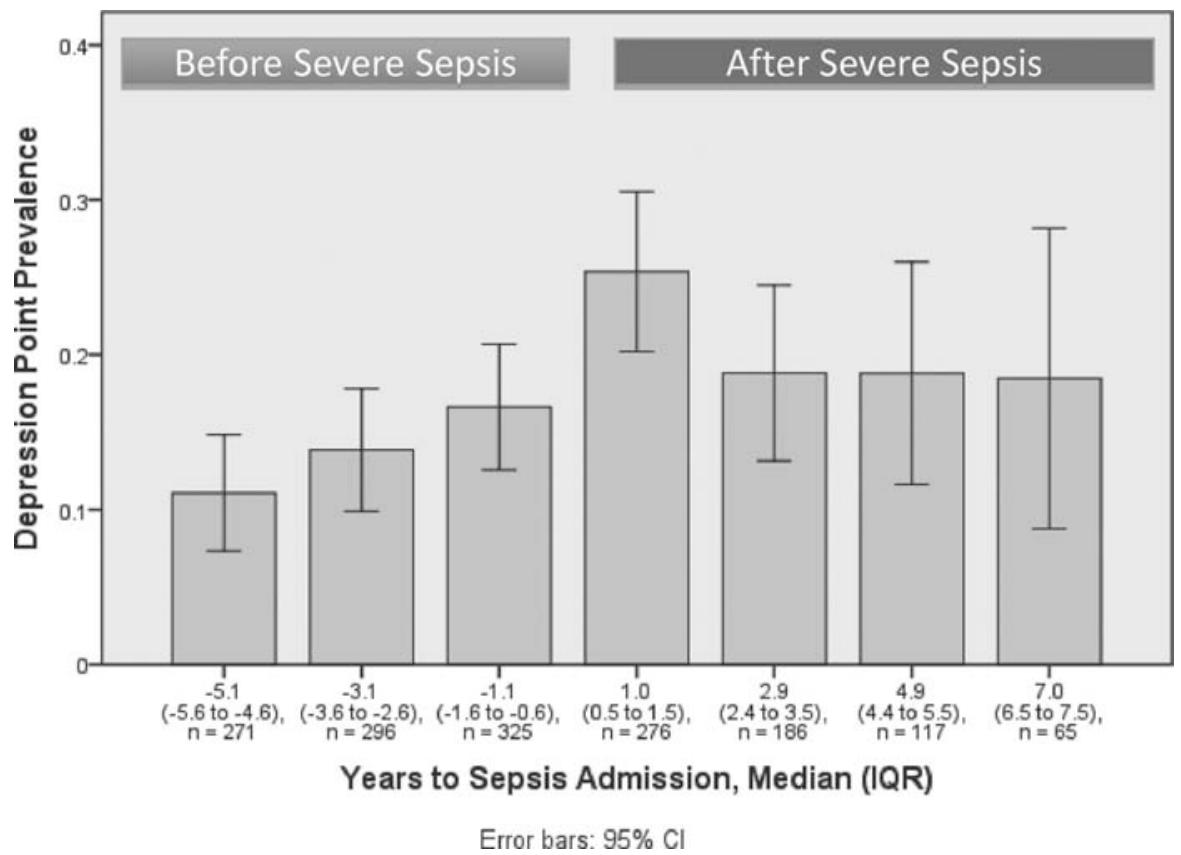

Figure 3. Prevalence of substantial depressive symptoms among husbands of patients with severe sepsis. $I Q R$, interquartile range; $C I$, confidence interval.

Wives of severe sepsis survivors who were disabled were more likely to have substantial depressive symptoms (odds ratio 1.35 per ADL limitation of sepsis survivor, 95\% CI: 1.12, 1.64). However, controlling for patient disability appeared to somewhat attenuate the association between husband sepsis and spousal substantial depressive symptoms (odds ratio $2.61,95 \%$ CI: $0.93,7.38$ ). For husbands, there was no evidence of increased depressive symptoms if their wives survived their sepsis episode (Table 3). For husbands, there was also no statistically significant association of substantial depressive symptoms with greater postsepsis disability in their wives.

\section{DISCUSSION}

In this nationally representative longitudinal investigation of older adults, we found that having a husband hospitalized for severe sepsis is associated with a near quadrupling of the odds of substantial symptoms of depression among wives, and a near tripling of the odds of substantial depressive symptoms if their husband survived sepsis, suggesting that our results are not explained by bereavement. Furthermore, each additional impairment of ADLs that a severe sepsis survivor had was associated with a $35 \%$ increase in the odds of substantial depressive symptoms in their wife, an association that could be reflective of the increased burdens of informal caregiving for a disabled older adult. To our knowledge, this study is the first investigation of depressive symptoms in spouses of older patients with severe sepsis that uses a standardized measure of depressive symptoms administered to spouses prospectively and prior to the patient's illness, and thereby to show clear evidence of a dramatic increase in rates of depressive symptoms among caregivers of severe sepsis.

While our data for wives are clear, we must acknowledge that the data for husbands are less definitive. There was a significant unadjusted association between having a wife hospitalized for severe sepsis and an increased prevalence of subsequent substantial depressive symptoms. However, this association was not significant in multivariate models, nor was the association between increasing ADL impairments in sepsis-surviving wives and substantial depressive symptoms in husbands. These findings could be due to response bias because of older men possibly being less willing to report depressive symptoms (36), as well as to insufficient statistical power given the wide CI surrounding the adjusted odds ratios for depressive symptoms in husbands. A clinically meaningful effect of sepsis on husbands is not completely ruled out by these results.

These findings have important implications for the growing literature on the central importance of spouses to the care of critically ill patients. Spouses have been well recognized to play a crucial but challenging role as surrogate decision makers for critically ill patients $(5,37,38)$. Similar to prior studies of depression in community-dwelling older adults using questionnaire measures $(39,40)$, spouses of older patients hospitalized for severe sepsis in our study had relatively high rates $(20 \%$ in wives and $17 \%$ in husbands) of substantial depressive symptoms during the year prior to the sepsis episode. Depression in spouses of critically ill sepsis patients could affect patient care decisions due to 
Table 2. Associations between having a husband hospitalized with severe sepsis and subsequent substantial depressive symptoms among wives ${ }^{a}$

\begin{tabular}{|c|c|c|c|}
\hline & \multicolumn{3}{|c|}{ Odds Ratio (95\% Confidence Interval) } \\
\hline & Among All Wives & $\begin{array}{c}\text { Among Wives } \\
\text { With Surviving } \\
\text { Husbands (Stratified } \\
\text { by Patient Survival) }\end{array}$ & $\begin{array}{l}\text { Among Wives With } \\
\text { Surviving Husbands } \\
\text { Adjusted for Husband's } \\
\text { Postsepsis Disability }\end{array}$ \\
\hline $\begin{array}{l}\text { Before sepsis } \\
\quad \text { (per additional year) }\end{array}$ & $1.07(0.87-1.32)$ & $1.11(0.73-1.68)$ & $0.98(0.62-1.55)$ \\
\hline Effect of sepsis & $3.74(2.20-6.37)^{d}$ & $2.86(1.06-7.73)^{b}$ & $2.61(0.93-7.38)$ \\
\hline $\begin{array}{l}\text { After sepsis } \\
\quad \text { (per additional year) }\end{array}$ & $0.73(0.60-0.90)^{c}$ & $0.84(0.45-1.15)$ & $0.82(0.43-1.59)$ \\
\hline $\begin{array}{l}\text { Sepsis survivor } \\
\text { activities of daily } \\
\text { living impairment }\end{array}$ & & & $1.35(1.12-1.64)^{c}$ \\
\hline
\end{tabular}

${ }^{a}$ Results of fixed effects logistic regression with hospitalization-level fixed effects stratified by gender, controlling for all time-invariant characteristics of the spouse; ${ }^{b} p<.05 ;{ }^{c} p<.01 ;{ }^{d} p<.001$.

Table 3. Associations between having a wife hospitalized with severe sepsis and subsequent substantial depressive symptoms among husbands ${ }^{a}$

\begin{tabular}{lccc}
\hline & \multicolumn{3}{c}{ Odds Ratio (95\% Confidence Interval) } \\
\cline { 2 - 4 } & Among All Husbands & $\begin{array}{c}\text { Among Husbands } \\
\text { With Surviving } \\
\text { Wives (Stratified by } \\
\text { Patient Survival) }\end{array}$ & $\begin{array}{c}\text { Among Husbands } \\
\text { With Surviving Wives } \\
\text { Adjusted for Wife's } \\
\text { Postsepsis Disability }\end{array}$ \\
\hline $\begin{array}{l}\text { Before sepsis } \\
\text { (per additional year) }\end{array}$ & $1.36(0.92-2.01)$ & $1.87(0.86-4.04)$ & $1.65(0.76-3.62)$ \\
$\begin{array}{l}\text { Effect of sepsis } \\
\text { After sepsis } \\
\text { (per additional year) }\end{array}$ & $0.83(0.64-1.08)$ & $0.72(0.12-4.25)$ & $0.63(0.10-4.01)$ \\
$\begin{array}{c}\text { Sepsis survivor } \\
\text { activities of daily } \\
\text { living impairment }\end{array}$ & $1.90(0.42-2.94)$ & $1.17(0.43-3.15)$ \\
\hline
\end{tabular}

${ }^{a}$ Results of fixed effects logistic regression with hospitalization-level fixed effects stratified by gender, controlling for all time-invariant characteristics of the spouse.

the spouse overestimating the risks and underestimating the benefits of a suggested course of treatment and/or impairing their decision-making abilities $(5,41)$. This may explain some of the remarkable challenges in information processing noted in decision making by surrogates (42). Even as a spouse's presepsis depression may have implications for ICU decision making, there is evidence that the processes of ICU decision making and care may impact spousal mental health after the critical illness experience (9). For example, one important randomized controlled trial showed that relatively modest changes to enhance communication during family meetings in French ICUs could reduce short-term levels of anxiety and depression among spouses of dying critically ill patients (43). Additional study is warranted to see if these or other ICUbased interventions could prevent longerterm depressive symptoms in spouses of the spouses of severe sepsis survivors, and its relationship to disability among those survivors.

Disability after severe sepsis is very common. In a related cohort of older Americans, over $59 \%$ of severe sepsis survivors had worse cognitive or physical function after their sepsis hospitalization (3). Our data demonstrate that each additional limitation in an ADL for a survivor of severe sepsis is associated with a clinically and statistically significant increase in the odds of substantial depressive symptoms for his wife, consistent with prior studies that have found that wives are more likely to be the primary caregiver for their disabled husbands than vice versa (33), and that female caregivers are at increased risk of depression compared to male caregivers across a wide range of populations due to the physical and emotional burdens of caregiving (49-52). The present study adds important urgency to ongoing clinical and research efforts to reduce disability in older adults surviving serious medical illnesses $(53,54)$ and to provide appropriate multidisciplinary resources to facilitate rehabilitation. Beyond the direct benefits to the patients and to society of having less disability in sepsis survivors, such efforts might also reduce the burden of depression on surviving spouses, particularly important in the light of work demonstrating the adverse health outcomes of older caregivers with emotional distress (55), and the negative health effects of depression on older adults (56). To the extent that depressed spouses are less able to support patients in ongoing rehabilitation, mental health interventions for spouses might be hypothesized to be an efficacious way to improve the outcomes of patients themselves.

Our findings also argue for strong consideration among clinicians on providing ongoing support and potential mental health screening for spouses as part of a comprehensive program of patient and family-centered post-ICU care. Furthermore, providers must learn to assess the burden that postdischarge follow-up plans may place on the patient's spouse, and consider their feasibility and vulnerability to reduced spousal participation due to depression. Also, nonspousal family members and support networks could be brought in to help facilitate the patient's post-ICU recovery. Prior work has identified that adult children of older 
adults with chronic illnesses could be an important resource for providing additional support (57), and future investigations in the context of critical illnesses could elucidate the importance of adult children and other support networks in the postillness recovery period.

Our study does have several limitations. Because we studied older Americans, the associations with severe sepsis and spousal depressive symptoms may be different in younger spouses. Furthermore, due to the methodology of our cohort, we cannot comment on the potential effects of severe sepsis on the emotional well-being of nonspousal caregivers. Also, since we assessed depressive symptoms with a questionnaire and not a diagnostic interview, a diagnosis of major depression could not be made. The eight-item Center for Epidemiologic Studies Depression Scale has been used in many relevant populations $(4,30-32)$, but it has not been specifically validated for use in spouses of patients with severe sepsis. Furthermore, we used a claimsbased definition of severe sepsis, which although not the same as prospective clinical assessment, has been validated and widely used (1, 17-20). In addition, we did not have a measure of illness severity related to the severe sepsis hospitalization, so we could not investigate the potential role of severity of sepsis as a predictor or effect modifier of spousal depression. Finally, the possibility of residual confounding remains as in any observational study.

\section{CONCLUSIONS}

Using a nationally representative sample of older adults, we found that wives of patients hospitalized with severe sepsis may be at significantly greater risk for substantial depressive symptoms following their spouses' sepsis episode, and that this association is present in the majority of wives whose husbands survive hospitalization. We also identified that wives of older men who survive severe sepsis with lasting disabilities have increased odds of substantial depressive symptoms. Future research focusing on improving communication between providers and spouses of severe sepsis patients along with interventions that increase identification and treatment facilitation of depression in spouses of patients with severe sepsis, could improve the health and quality of life for this growing population of older Americans.

\section{ACKNOWLEDGMENT}

We appreciate the expert programming of Tish Shapiro and Mohammed Kabeto, both at the University of Michigan.

\section{REFERENCES}

1. Angus DC, Linde-Zwirble WT, Lidicker J, et al: Epidemiology of severe sepsis in the United States: Analysis of incidence, outcome, and associated costs of care. Crit Care Med 2001; 29:1303-1310

2. Winters BD, Eberlein M, Leung J, et al: Longterm mortality and quality of life in sepsis: A systematic review. Crit Care Med 2010; 38:1276-1283

3. Iwashyna TJ, Ely EW, Smith DM, et al: Longterm cognitive impairment and functional disability among survivors of severe sepsis. JAMA 2010; 304:1787-1794

4. Davydow DS, Hough CL, Langa KM, et al: Symptoms of depression in survivors of severe sepsis: A prospective cohort study of older Americans. Am J Geriatr Psychiatry 2012 Jun 15. [Epub ahead of print]

5. Pochard F, Azoulay E, Chevret S, et al; French FAMIREA Group: Symptoms of anxiety and depression in family members of intensive care unit patients: Ethical hypothesis regarding decision-making capacity. Crit Care Med 2001; 29:1893-1897

6. Azoulay E, Pochard F, Kentish-Barnes N, et al: FAMIREA Study Group: Risk of post-traumatic stress symptoms in family members of intensive care unit patients. Am J Respir Crit Care Med 2005; 171:987-994

7. Anderson WG, Arnold RM, Angus DC, et al: Posttraumatic stress and complicated grief in family members of patients in the intensive care unit. J Gen Intern Med 2008; 23:1871-1876

8. McAdam JL, Dracup KA, White DB, et al: Symptom experiences of family members of intensive care unit patients at high risk for dying. Crit Care Med 2010; 38:1078-1085

9. Gries CJ, Engelberg RA, Kross EK, et al: Predictors of symptoms of posttraumatic stress and depression in family members after patient death in the ICU. Chest 2010; 137:280-287

10. Cameron ID, Aggar C, Robinson AL, et al: Assessing and helping carers of older people. BMJ 2011; 343:d5202

11. Langa KM, Chernew ME, Kabeto MU, et al: National estimates of the quantity and cost of informal caregiving for the elderly with dementia. J Gen Intern Med 2001; 16:770-778

12. Cole MG, Dendukuri N: Risk factors for depression among elderly community subjects: A systematic review and meta-analysis. Am J Psychiatry 2003; 160:1147-1156

13. Gifford JM, Husain N, Dinglas VD, et al: Baseline quality of life before intensive care: A comparison of patient versus proxy responses. Crit Care Med 2010; 38:855-860

14. Health and Retirement Study: Sample sizes and response rates. Available at: http://hrsonline. isr.umich.edu/sitedocs/sampleresponse.pdf. Accessed March 6, 2011
15. Elixhauser A, Steiner C, Harris DR, et al: Comorbidity measures for use with administrative data. Med Care 1998; 36:8-27

16. Quan H, Sundararajan V, Halfon P, et al: Coding algorithms for defining comorbidities in ICD-9-CM and ICD-10 administrative data. Med Care 2005; 43:1130-1139

17. Martin GS, Mannino DM, Eaton S, et al: Theepidemiologyofsepsisinthe United States from 19792000. NEnglJMed 2003; 34: 1546-1554

18. Levy MM, Fink MP, Marshall JC, et al: SCCM/ ESICM/ACCP/ATS/SIS: 2001 SCCM/ESICM/ ACCP/ATS/SIS International Sepsis Definitions Conference. Crit Care Med 2003; 31:1250-1256

19. Weycker D, Akhras KS, Edelsberg J, et al: Long-term mortality and medical care charges in patients with severe sepsis. Crit Care Med 2003; 31:2316-2323

20. Lee H, Doig CJ, Ghali WA, et al: Detailed cost analysis of care for survivors of severe sepsis. Crit Care Med 2004; 32:981-985

21. Angus DC: Management of sepsis: A 47-year-old woman with an indwelling intravenous catheter and sepsis. JAMA 2011; 305:1469-1477

22. Annane D, Bellissant E, Cavaillon JM: Septic shock. Lancet $2005 ; 365: 63-78$

23. Dellinger RP, Levy MM, Carlet JM, et al: International Surviving Sepsis Campaign Guidelines Committee; American Association of Critical-Care Nurses; American College of Chest Physicians; American College of Emergency Physicians; Canadian Critical Care Society; European Society of Clinical Microbiology and Infectious Diseases; European Society of Intensive Care Medicine; European Respiratory Society; International Sepsis Forum; Japanese Association for Acute Medicine; Japanese Society of Intensive Care Medicine; Society of Critical Care Medicine; Society of Hospital Medicine; Surgical Infection Society; World Federation of Societies of Intensive and Critical Care Medicine: Surviving Sepsis Campaign: International guidelines for management of severe sepsis and septic shock: 2008. Crit Care Med 2008; 36:296-327

24. Zahar JR, Timsit JF, Garrouste-Orgeas M, et al: Outcomes in severe sepsis and patients with septic shock: Pathogen species and infection sites are not associated with mortality. Crit Care Med 2011; 39:1886-1895

25. Radloff LS: The CES-D Scale: A self-report depression scale for research in the general population. Appl Psychol Meas 1977; 1:385-401

26. Soldo BJ, Hurd MD, Rodgers WL, et al: Asset and Health Dynamics Among the Oldest Old: An overview of the AHEAD Study. $J$ Gerontol B Psychol Sci Soc Sci 1997; 52 Spec No:1-20

27. Kohout FJ, Berkman LF, Evans DA, et al: Two shorter forms of the CES-D (Center for Epidemiological Studies Depression) depression symptoms index. J Aging Health 1993; 5:179-193

28. Turvey CL, Wallace RB, Herzog R: A revised CES-D measure of depressive symptoms and a DSM-based measure of major depressive 
episodes in the elderly. Int Psychogeriatr 1999; 11:139-148

29. Steffick DE: Documentation of Affective Functioning Measures in the Health and Retirement Study. Ann Arbor, Michigan, Survey Research Center; 2000

30. Langa KM, Valenstein MA, Fendrick AM, et al: Extent and cost of informal caregiving for older Americans with symptoms of depression. Am J Psychiatry 2004; 161:857-863

31. Zivin K, Llewellyn DJ, Lang IA, et al: Depression among older adults in the United States and England. Am J Geriatr Psychiatry 2010; 18:1036-1044

32. Mezuk B, Bohnert AS, Ratliff S, et al: Job strain, depressive symptoms, and drinking behavior among older adults: Results from the health and retirement study. $J$ Gerontol B Psychol Sci Soc Sci 2011; 66:426-434

33. Katz SJ, Kabeto M, Langa KM: Gender disparities in the receipt of home care for elderly people with disability in the United States. JAMA 2000; 284:3022-3027

34. Allison PD: Fixed Effects Regression Models. Thousand Oaks, Sage, 2009

35. Farewell VT: Fixed Effects. In: Encyclopedia of Biostatistics. Vol. 2. Armitage P, (ed): New York, John Wiley, 1998, pp1533

36. Eaton WW, Neufeld K, Chen LS, et al: A comparison of self-report and clinical diagnostic interviews for depression: Diagnostic interview schedule and schedules for clinical assessment in neuropsychiatry in the Baltimore epidemiologic catchment area followup. Arch Gen Psychiatry 2000; 57:217-222

37. Boyd EA, Lo B, Evans LR, et al: "It's not just what the doctor tells me:" factors that influence surrogate decision-makers' perceptions of prognosis. Crit Care Med 2010; 38:1270-1275

38. Apatira L, Boyd EA, Malvar G, et al: Hope, truth, and preparing for death: perspectives of surrogate decision makers. Ann Intern Med 2008; 149:861-868

39. Han B: The impact of age, gender, and race on the relationship between depression and selfrated health in community-dwelling older adults: A longitudinal study. Home Health Care Serv Q 2001; 20:27-43

40. Solhaug HI, Romuld EB, Romild U, et al: Increased prevalence of depression in cohorts of the elderly: An 11-year follow-up in the general population - the HUNT study. Int Psychogeriatr 2012; 24:151-158

41. Blank K, Robison J, Doherty E, et al: Life-sustaining treatment and assisted death choices in depressed older patients. J Am Geriatr Soc 2001; 49:153-161

42. White DB: Rethinking interventions to improve surrogate decision making in intensive care units. Am J Crit Care 2011; 20:252-257

43. Lautrette A, Darmon M, Megarbane B, et al: A communication strategy and brochure for relatives of patients dying in the ICU. $N$ Engl J Med 2007; 356:469-478

44. Cameron JI, Herridge MS, Tansey CM, et al: Well-being in informal caregivers of survivors of acute respiratory distress syndrome. Crit Care Med 2006; 34:81-86

45. Cox CE, Docherty SL, Brandon DH, et al: Surviving critical illness: Acute respiratory distress syndrome as experienced by patients and their caregivers. Crit Care Med 2009; 37:2702-2708

46. Kersting A, Brähler E, Glaesmer $\mathrm{H}$, et al: Prevalence of complicated grief in a representative population-based sample. $J$ Affect Disord 2011; 131:339-343

47. Zivin K, Christakis NA: The emotional toll of spousal morbidity and mortality. Am J Geriatr Psychiatry 2007; 15:772-779

48. Taylor DH Jr, Kuchibhatla M, Ostbye T, et al: The effect of spousal caregiving and bereavement on depressive symptoms. Aging Ment Health 2008; 12:100-107

49. Holtzman S, Abbey SE, Singer LG, et al: Both patient and caregiver gender impact depressive symptoms among organ transplant caregivers: Who is at risk and why? J Health Psychol 2011; 16:843-856

50. Sugiura K, Ito M, Kutsumi M, et al: Gender differences in spousal caregiving in Japan. J Gerontol B Psychol Sci Soc Sci 2009; 64:147-156

51. Pinquart M, Sörensen S: Gender differences in caregiver stressors, social resources, and health: An updated meta-analysis. $J$ Gerontol B Psychol Sci Soc Sci 2006; 61:P33-P45

52. Covinsky KE, Newcomer R, Fox P, et al: Patient and caregiver characteristics associated with depression in caregivers of patients with dementia. J Gen Intern Med 2003; 18:1006-1014

53. Schweickert WD, Pohlman MC, Pohlman AS, et al: Early physical and occupational therapy in mechanically ventilated, critically ill patients: A randomised controlled trial. Lancet 2009; 373:1874-1882

54. Needham DM, Korupolu R, Zanni JM, et al: Early physical medicine and rehabilitation for patients with acute respiratory failure: A quality improvement project. Arch Phys Med Rehabil 2010; 91:536-542

55. Schulz R, Beach SR: Caregiving as a risk factor for mortality: The Caregiver Health Effects Study. JAMA 1999; 282:2215-2219

56. Katon WJ: Clinical and health services relationships between major depression, depressive symptoms, and general medical illness. Biol Psychiatry 2003; 54:216-226

57. Piette JD, Rosland AM, Silveira M, et al: The case for involving adult children outside of the household in the self-management support of older adults with chronic illnesses. Chronic Illn 2010; 6:34-45 